\title{
Editorial: Tourism and Social Regeneration
}

\author{
Nicholas Wise \\ Faculty of Education, Health and Community, Sport Studies, Leisure and Nutrition School, \\ Liverpool John Moores University, Liverpool L17 6BD, UK; N.A.Wise@ljmu.ac.uk
}

Received: 6 December 2018; Accepted: 6 December 2018; Published: 10 December 2018

\begin{abstract}
Research on social regeneration is a very specific area that needs more attention in the tourism and social sciences literature. Whilst much research has focused attention on tourism developments and regeneration efforts, this work is more concerning with the physical transformation of spaces (such as upgrading facilities and infrastructures) or expanding investments in tourism and visitor attractions. Planners and policy makers are concerned with maintaining a competitive advantage, resulting in policies and investments aimed at developing spaces in transition for the purpose of economic gain and/or image revival. To go beyond the focus on economic impacts of tourism-led regeneration, the purpose of this special issue is to address the importance of, and the need to, critically assess issues, problems and solutions surrounding social regeneration resulting from tourism change, developments or initiatives. More research considering how members of a community and event attendees engage with spaces and places transformed for tourism is needed. Paying closer attention to intangible impacts to extend recent debates surrounding tourism initiatives, involvement and futures is needed, emphasizing improved welfare and empowering local communities and its residents. The papers included in this special issue all put emphasis on the community and/or local residents and how they are impacted by tourism investments or initiatives.
\end{abstract}

Keywords: social regeneration; social impacts; tourism and change; community; tourism social policy

Much research has focused attention on tourism developments and regeneration efforts. Regeneration is often regarded as the process of renewal or redevelopment of existing facilities and infrastructures, and thus, expansions for, or new investments in, tourism and visitor attractions align with contemporary regeneration strategies and initiatives linked to transitioning economic bases. Planners and policy makers are concerned with maintaining a competitive advantage, resulting in policies and investments aimed at developing spaces in transition for the purpose of economic gain and/or image revival. To go beyond the focus on economic impacts of tourism-led regeneration, the purpose of this special issue is to address the importance of, and the need for, critically assessing issues, problems, and solutions surrounding social regeneration resulting from tourism change, developments, or initiatives.

More research considering how members of a community, visitors, and event attendees engage with spaces and places transformed for tourism is needed, as this extends our understanding of tourism and social regeneration. Paying closer attention to intangible impacts to extend recent debates surrounding tourism initiatives, involvement, and futures is needed, emphasizing improved welfare and empowering local communities and their residents. Evaluating differing trends associated with social regeneration, including discussions and critiques of existing policies, or the lack of insight and initiatives among planners, policy makers, and members of the community concerning tourism, is an attempt to debate new directions concerning tourism, social impacts, and social policy. The goal of this special issue is to bring together both international and interdisciplinary perspectives, through submissions that test conceptual boundaries, offer a critique of social policy, or provide evidence from a specific case (or cases). 
Smith (2012) assesses social impacts and social regeneration. Regeneration is important to consider as a holistic concept that is important because in theory and practice discussions are integrated in the social sciences and management studies. One of the main impacts of regeneration is to frame how opportunities are further developed, and from a social regeneration standpoint, these opportunities and experiences are linked to how people and society benefit from tourism (Perić et al. 2017; Perić et al. 2018; Wise and Perić 2017). Richards and Palmer (2010) argue that places need to keep up with the pace of change or they risk stagnation and decline as increased competition has led to a new range of opportunities, not only in terms of tangible gains and benefits but also intangible impacts (AlBalushi and Wise 2017; Hong 2014; Scholtz and Slabbert 2016; Smith 2005; Wise et al. 2015; Wise et al. 2017).

Tourism developments and regeneration in the 1980s were primarily public sector led using taxpayer money to fund infrastructure projects (Cowan 2016). In the late 1980s, and even more so into the 1990s, partnerships between the public and private sector started to emerge and change how projects in cities were funded, financed, and where profits were directed (Smith 2012). For instance, the emergence of joint stock companies, partnerships between public and private sector, resulted in clustering (Franco and Estevão 2010). The intension was to build on the strengths of shared resources and knowledge transfer to contribute added value to products being offered and delivered for the purpose of economic regeneration (Deakin and Edwards 1993; Tallon 2010). Much research has considered the role of how sport has been used as a driver to add further value to destinations (e.g., Gratton and Henry 2001; Perić et al. 2016; Wise and Hall 2017; Wise and Harris 2017) or how events in transforming opportunities, and some of these discussions link regeneration and tourism as well. For instance, Smith (2012, p. 174) suggests "a producer of sport, as well as a site for its consumption" helps to diversify opportunities for local residents. There is also a need to consider issues of inclusion and exclusion (Clark and Wise 2018; Wise and Harris 2017) and how value is delivered (see Perić and Wise 2015).

Concerning tourism and social regeneration, Spirou (2011) argues that change affects the image of a destination, which has implications on management and planning for locals and tourists. Cowan (2016) adds that planning needs to be inclusive and enable more residents opposed to creating barriers that limit involvement. Much research has focused on critically assessing communities and social understandings linked to local perceptions of tourism, social tourism, and community development (e.g., Deery et al. 2012; Dwyer 2005; Wise and Whittam 2015). Work in this area has close conceptual links with social regeneration putting emphasis on the community, or community-based tourism (Đurkin and Wise 2018), and is discussed in this special issue. It is also important for communities to leverage social outcomes, and take advantage of what approaches, involvement and social capital is needed so that tourism regeneration will be most beneficial to the general public. There can be community initiatives but some places need social policies to enable people to get involved and participate. Putnam (2000) addressed social capital, but bonding capital focuses on the forging of community ties that lend to a greater sense of belonging, or sense of community (Wise 2015). Community and social conditions are also important when assessing competitiveness. Much research has gained insight on how tourism has impacted a place from the standpoint of vested tourism stakeholders (e.g., Mulec and Wise 2013; Pulido-Fernández and Rodríguez-Díaz 2016), but it is important to gain such insight from the perspective of local residents as places invest heavily in changes (see Aquilino et al. 2018).

To outline issues concerning tourism and social regeneration, from a policy standpoint governments and public sector organizations need to further measure social impacts and social conditions. Moreover, policy initiatives focus on improving local wellbeing through planning for tourism (Vogt et al. 2016). Positive socio-cultural impacts are based on education, local experiences, improvements to residential facilities, maintaining cultural traditions and local artefacts, and increased civic pride (see Smith 2012; Spirou 2011). For example, the UNWTO Manila Declaration in 1980 addressed social impacts of tourism in relation to rapidly changing tourism trends and dynamics. 
Moreover, as Wise (2016, p. 32) argues: "numerous negative impacts on people and communities relate to the commodification of culture, violations of human rights, increased social problems, social demonstrations, loss of traditional industries, alterations in traditional codes (e.g., practices, values, religion) and community fragmentation."

Increasingly, academics are concerned with how plans for developing tourism emphasize social legacy, or 'softer' impacts (Stevenson 2013; Wise and Clark 2017; Wise and Harris 2017). Scholars have argued that infrastructures and venues are attempts to spark economic generation, which can help improve visitor profiles or enhance the image of a city (Spirou et al. 2017). Moreover, Lawless (2010) argues that social benefits and legacies are lost in the process as cities regenerate. This is because funds can easily be redistributed, or when hidden costs emerge this takes away from investing in social impacts because money is needed for purposes that are more tangible. As Wise (2016) notes, many urban tourism projects are financed, supported, and maintained through private sector funds-and this can then limit opportunities for local residents and also exclude them assess. Cowan (2016) argues private investments results in 'islands' where those who can afford to consume are welcome, and those who cannot are spatially excluded from such spaces of privilege.

To summarize some of the wider conceptual points, social regeneration, social impacts, and social change are about altering peoples' outlook and attitude of their place, as well as gaining support to encourage cohesive involvement among members of a community (Deery et al. 2012; Dwyer 2005). Moreover, how communities seek innovative ways to enhance social interactions, which is explored in this special issue. Thwaites et al. (2013) adds that individual and social capital (and arguably community capital) need to further research-and this is explored in this special issue. Social capital involves the formation of networks, norms, and trusts. With such trust and collaboration enables people to work together to peruse and achieve a number of set shared objectives (Wise 2016). This is essential as places transform and generate tourism opportunities, as urban, regional and rural developments can potentially have long-term impacts on societal/social relationships between city governments/planners and communities. Some may view investments in tourism as investments in someone else's interests and not necessarily the needs of the local residents (Spirou 2011). Therefore, new approaches to tourism planning and associated developments need to address how changes will impact the city and community collectively-again, in terms of creating a sense of social cohesion, pride in place, and a collective sense of identity (Pookaiyaudom 2015). From a methodological standpoint, social regeneration and social impacts are difficult to measure, but the focus in future research needs to further acknowledge notions of inclusion and exclusion. The papers in this special issue offer different methodological and theoretical insights. One important question, as Wise and Whittam (2015) remark, is to critical consider: who is regeneration for? This becomes especially important when conducting research on social regeneration, as researchers assess and evaluate who gains and who does not from tourism.

There are three papers included in this special issue. It must be noted that this is a very niche area of research that needs and deserves more attention to expand on some of the conceptual points and issues outline above. This in part can explain why there were only three papers included in this special issue. The first paper by Marko Perić titled Estimating the Perceived Socio-Economic Impacts of Hosting Large-Scale Sport Tourism Events focuses on the 2018 EHF European Handball Championship held in Croatia. Large-scale sport events such as the EHF European Handball Championship help attract a wide range of attendees, resulting in various implications for the host community. This paper is concerned with understanding the legacy of the 13th EHF European Handball Championship, held in Croatia in January 2018, by assessing the event's economic and social benefits and costs. The paper draws on Social Exchange Theory to examine if there are any significant differences that exist between host city residents and non-host city residents regarding perceived impacts of the 13th EHF European Handball Championship. The number of impacts were reduced by conducting an exploratory factor analysis and differences between host city and non-host city residents were examined by an independent samples $t$-test. Key findings show that community development and 
pride, security risks, traffic problems, economic benefits, environmental concerns, and economic costs were the main impact dimensions. Results also indicated that non-host city residents expressed a higher level of agreement with most of the impacts. Significant differences did exist, primarily within the dimensions of community development and pride, economic benefits, traffic problems, and environmental concerns. Such work is useful for event planners and sport marketers when trying to acquire community-wide support gain insight based on resident (and non-resident) perceptions.

The second paper by María D. Torres-Alruiz, Marisela J. Pilquimán V. and Christian Henríquez-Zúñiga titled Resilience and Community-Based Tourism: Mapuche Experiences in Pre-Cordilleran Areas (Puyehue and Panguipulli) of Southern Chile focuses on resilience, community-based tourism, and mapuche communities. The authors argue for more work concerning community-based tourism in Latin America, as there is a need to focus on and emphasize community impacts and sustainability. In this study, socio-ecological and situated narratives of resilience are enriched to examine to understand community based tourism experiences. The work is based on longitudinal participatory action research projects since 2013 (in Puyehue and Panguipulli). Results show that the socio-ecological narrative is useful, but also insufficient. They argue the relevance of the situated narrative seems to be more effective to engage in dialogue and joint work with mapuche communities. Building on the second paper, the next paper puts more emphasis on innovation and community engagement. The third paper by Lars Fuglsang and Anne Nordli titled On Service Innovation as an Interactive Process: A Case Study of the Engagement with Innovation of a Tourism Service focuses on service innovation, engagement theory, the use of narrative method, and interactive capabilities. The authors argue that innovation is an interactive process that engages numerous actors over time, which contribute to the regeneration of goods and services, and this concerns the role of community actors in such changes. They also argue that little work has assessed how actors grasp the societal environment in which they interact. For example, this concerns relationships/interactions with a wider community - and how interaction formats affect innovation. The paper contributes to the work on social regeneration because it stresses service and tourism needs innovative engagement to assess and address social interactions between innovators and their social environment. The paper suggest that different formats of engagement need balanced as part of the innovation process. This editorial positions the focus of regeneration in tourism research, and now turns to the papers included in this special issue.

Funding: This research received no external funding.

Conflicts of Interest: The authors declare no conflict of interest.

\section{References}

AlBalushi, Ammar Abdulrahman, and Nicholas Wise. 2017. Planning for Tourism in Oman based on Lessons from Dubai: Overviewing Economic, Environmental and Socio-Cultural Impacts. In Tourism in the Arab World: An Industry Perspective. Edited by Hamed Almuhrzi, Hafidh Alriyami and Noel Scott. Bristol: Channel View Publications, ISBN 978-1-845-41614-0.

Aquilino, Lucia, Tanja Armenski, and Nicholas Wise. 2018. Assessing the competitiveness of Matera and the Basilicata Region (Italy) ahead of the 2019 European Capital of Culture. Tourism and Hospitality Research. [CrossRef]

Clark, Julie, and Nicholas Wise, eds. 2018. Urban Renewal, Community and Participation: Theory, Policy and Practice. Berlin: Springer, ISBN 978-3-319-72311-2.

Cowan, Aaron. 2016. A Nice Place to Visit: Tourism and Urban Revitalization in the Postwar Rustbelt. Philadelphia: Temple University Press, ISBN 978-1-439-91346-8.

Deakin, Nicholas, and John Edwards. 1993. The Enterprise Culture and the Inner City. London: Routledge.

Deery, Margaret, Leo Jago, and Liz Fredline. 2012. Rethinking social impacts of tourism research: A new research agenda. Tourism Management 33: 64-73. [CrossRef] 
Đurkin, Jelena, and Nicholas Wise. 2018. Managing community stakeholders in rural areas: Assessing the organisation of local sports events in Gorski kotar, Croatia. In Power, Construction and Meaning in Festivals $\mathcal{E}$ Events. Edited by Allan Jepson and Alan Clarke. London: Routledge, pp. 185-200. ISBN 978-1-138-06322-8.

Dwyer, Larry. 2005. Relevance of triple bottom line reporting to achievement of sustainable tourism: A scoping study. Tourism Review International 9: 79-93. [CrossRef]

Franco, Mário, and Cristina Estevão. 2010. The role of tourism public-private partnerships in regional development: A conceptual model proposal. CADERNOS EBAPE 8: 600-12. [CrossRef]

Gratton, Chris, and Ian Henry, eds. 2001. Sport in the City: The Role of Sport in Economic and Social Regeneration. London: Routledge, ISBN 978-0-415-24349-0.

Hong, Ju. 2014. Study on urban tourism development based on experience economy in Shanghai. International Journal of Business and Social Science 5: 59-63.

Lawless, Paul. 2010. Urban regeneration: Is there a future? People, Place and Policy Online 4: 24-28. [CrossRef]

Mulec, Ivo, and Nicholas Wise. 2013. Indicating the competitiveness of Serbia's Vojvodina region as an emerging tourism destination. Tourism Management Perspectives 8: 68-79. [CrossRef]

Perić, Marko, and Nicholas Wise. 2015. Understanding the delivery of experience: Conceptualising business models and sports tourism, assessing two case studies in Istria, Croatia. Local Economy 30: 1000-16. [CrossRef]

Perić, Marko, Vanja Vitezić, and Janez Mekinc. 2016. Conceptualising innovative business models for sustainable sport tourism. International Journal of Sustainable Development and Planning 11: 469-82. [CrossRef]

Perić, Marko, Nicholas Wise, and Daniel Dragičević. 2017. Suggesting a service research agenda in sport tourism: Working experience(s) into business models. Sport, Business and Management: an International Journal 7: 58-76. [CrossRef]

Perić, Marko, Jelena Đurkin, and Vanja Vitezić. 2018. Active event sport tourism experience: The role of the natural environment, safety and security in event business models. International Journal of Sustainable Development and Planning 13: 758-72. [CrossRef]

Pookaiyaudom, Gulapish. 2015. Relationship between community pride and participation needs in sustainable tourism development of Fishing Village: A case study of Samut Sakhon Province, Thailand. WIT Transactions on Ecology and The Environment 192: 343-54. [CrossRef]

Pulido-Fernández, Juan Ignacio, and Beatriz Rodríguez-Díaz. 2016. Reinterpreting the World Economic Forum's global tourism competitiveness index. Tourism Management Perspectives 20: 131-40. [CrossRef]

Putnam, Robert. 2000. Bowling Along: The Collapse and Revival of American Community. New York: Simon \& Schuster, ISBN 978-0-743-20304-3.

Richards, Greg, and Robert Palmer. 2010. Eventful Cities: Cultural Management and Urban Revitalisation. Oxford: Butterworth-Heinemann, ISBN 978-0-7506-6987-0.

Scholtz, Marco, and Elmarie Slabbert. 2016. The relevance of the tangible and intangible social impacts of tourism on selected South African communities. Journal of Tourism and Cultural Change 14: 107-28. [CrossRef]

Smith, Andrew. 2005. Conceptualizing image change: The reimagining of Barcelona. Tourism Geographies 7: $398-423$. [CrossRef]

Smith, Andrew. 2012. Events and Urban Regeneration: The Strategic Use of Events to Revitalise Cities. London: Routledge, ISBN 978-0-415-58148-6.

Spirou, Costas. 2011. Urban Tourism and Urban Change: Cities in a Global Economy. London: Routledge, ISBN 978-0-415-80163-8.

Spirou, Costas, Candice Miller, and Brandi Baker. 2017. Urban coalitions and the production of Atlanta's downtown. In Sport, Events, Tourism and Regeneration. Edited by Nicholas Wise and John Harris. London: Routledge, pp. 118-33. ISBN 978-1-13-864281-2.

Stevenson, Nancy. 2013. The Complexities of Tourism and Regeneration: The Case of the 2012 Olympic Games. Tourism Planning \& Development 10: 1-16.

Tallon, Andrew. 2010. Urban Regeneration in the UK. London: Routledge, ISBN 978-0-415-68503-0.

Thwaites, Kevin, Alice Mathers, and Ian Simkins. 2013. Socially Restorative Urbanism. London: Routledge, ISBN 978-0-415-59603-9.

Vogt, Christine A., Evan Jordan, Nicole Grewe, and Linda Kruger. 2016. Collaborative tourism planning and subjective well-being in a small island destination. Journal of Destination Marketing E Management 5: 36-43.

Wise, Nicholas. 2015. Placing sense of community. Journal of Community Psychology 43: 920-29. [CrossRef] 
Wise, Nicholas. 2016. Outlining Triple Bottom Line Contexts in Urban Tourism Regeneration. Cities 53: 30-34. [CrossRef]

Wise, Nicholas, and Julie Clark, eds. 2017. Urban Transformations: Geographies of Renewal and Creative Change. London: Routledge, ISBN 978-1-138-65209-5.

Wise, Nicholas, and Gareth Hall. 2017. Transforming Brazil: Sporting mega-events, tourism, geography and the need for sustainable regeneration in host cities. In Sport, Events, Tourism and Regeneration. Edited by Nicholas Wise and John Harris. London: Routledge, pp. 24-39. ISBN 978-1-13-864281-2.

Wise, Nicholas, and John Harris, eds. 2017. Sport, Events, Tourism and Regeneration. London: Routledge, ISBN 978-1-13-864281-2.

Wise, Nicholas, and Marko Perić. 2017. Sports tourism, regeneration and social impacts: New opportunities and directions for research, the case of Medulin, Croatia. In Tourism in the City: Towards an Integrative Agenda on Urban Tourism. Edited by Nicola Bellini and Cecilia Pasquinelli. Berlin: Springer, pp. 311-20. ISBN 978-3-319-26876-7.

Wise, Nicholas, and Geoff Whittam. 2015. Editorial: Regeneration, enterprise, sport and tourism. Local Economy 30: 867-70. [CrossRef]

Wise, Nicholas, Jenny Flinn, and Ivo Mulec. 2015. Exit Festival: Contesting Political Pasts, impacts on Youth Culture and Regenerating the Image of Serbia and Novi Sad. In Ideological, Social and Cultural Aspects of Events. Edited by Omar Moufakkir and Tomas Pernecky. Wallingford: CABI, pp. 60-73. ISBN 978-1-78064-352-6.

Wise, Nicholas, Ivo Mulec, and Tanja Armenski. 2017. Towards a new local tourism economy: Understanding sense of community, social impacts and potential enterprise opportunities in Podgrađe Bač, Vojvodina, Serbia. Local Economy 32: 656-77. [CrossRef]

(C) 2018 by the author. Licensee MDPI, Basel, Switzerland. This article is an open access article distributed under the terms and conditions of the Creative Commons Attribution (CC BY) license (http:/ / creativecommons.org/licenses/by/4.0/). 